\title{
Failure of carnitine in improving hepatic nitrogen content in alcoholic and non-alcoholic malnourished rats
}

\author{
Luciana P. Rodrigues, Guilherme Vannucchi Portari, Gilberto João Padovan, Alceu Afonso Jordão, \\ Vivian M. M. Suen, Julio Sergio Marchini \\ Faculdade de Medicina de Ribeirão Preto, Universidade de São Paulo, São Paulo, SP, Brazil.
}

\begin{abstract}
AIMS: To investigate the effect of carnitine supplementation on alcoholic malnourished rats' hepatic nitrogen content.

METHODS: Malnourished rats, on 50\% protein-calorie restriction with free access to water (malnutrition group) and malnourished rats under the same conditions with free access to a $20 \%$ alcohol/water solution (alcohol group) were studied. After the undernourishment period (4 weeks with or without alcohol), both groups were randomly divided into two subgroups, one of them nutritionally recovered for 28 days with free access to a normal diet and water (recovery groups) and the other re-fed with free access to diet and water plus carnitine $(0.1 \mathrm{~g} / \mathrm{g}$ body weight/day by gavage) (carnitine groups). No alcohol intake was allowed during the recovery period.
\end{abstract}

RESULTS: The results showed: i) no difference between the alcohol/no alcohol groups, with or without carnitine, regarding body weight gain, diet consumption, urinary nitrogen excretion, plasma free fatty acids, lysine, methionine, and glycine. ii) Liver nitrogen content was highest in the carnitine recovery non-alcoholic group (from 1.7 to $3.3 \mathrm{~g} / 100 \mathrm{~g}, P<0.05)$ and lowest in alcoholic animals (about $1.5 \mathrm{~g} / 100 \mathrm{~g})$. iii) Hepatic fat content $(\sim 10 \mathrm{~g} / 100 \mathrm{~g}$, $P>05)$ was highest in the alcoholic animals.

CONCLUSION: Carnitine supplementation did not induce better nutritional recovery.

KEYWORDS: L-carnitine; Undernourishment; Alcoholism; Liver nitrogen; Liver fat.

Rodrigues LP, Portari GV, Padovan GJ, Jordão AA, Suen VMM, Marchini JC. Failure of carnitine in improving hepatic nitrogen content in alcoholic and non-alcoholic malnourished rats. Clinics. 2010;65(9):877-883.

Received for publication on April 12, 2010; First review completed on May 29, 2010; Accepted for publication on June 17, 2010

E-mail: jsmarchi@fmrp.usp.br

Tel.: 16 3602-2563

\section{INTRODUCTION}

Protein-calorie undernourishment is one of the most frequent morbid conditions affecting hospitalized patients in both developed and developing countries. ${ }^{1,2}$ Alcoholism is a complicating associated factor that leads to undernourishment with increased mortality. ${ }^{3}$ Clinical studies have investigated several compounds as possible enhanced supplementation factors for the treatment of undernourishment, with particular emphasis on carnitine. ${ }^{4,5}$

Carnitine (L-3-hydroxy-4-N-N-N-trimethylaminobutyrate) is an essential metabolite that has a number of indispensable functions in intermediary metabolism, ${ }^{6}$ including mitochondrial fatty acid B-oxidation. ${ }^{7}$ Carnitine is synthesized from two essential amino acids, lysine and methionine, with ascorbic acid, niacin, vitamin B6, and iron acting as

Copyright (c) 2010 CLINICS - This is an Open Access article distributed under the terms of the Creative Commons Attribution Non-Commercial License (http:// creativecommons.org/licenses/by-nc/3.0/) which permits unrestricted noncommercial use, distribution, and reproduction in any medium, provided the original work is properly cited. co-factors. ${ }^{8}$ Besides the fact that carnitine depletion is common in patients hospitalized for advanced cirrhosis, ${ }^{9}$ it seems also to have a protective action after ethanol administration $^{10}$ but no beneficial effects in terms of hepatic oxidative stress. $^{11}$

Since L-carnitine is a compound with an important role in energy metabolism, its use as a nutritional supplement can improve the recovery of malnourished patients. However, there is controversy regarding its efficacy as a co-adjuvant in nutritional therapy. For example, the repletion weight gain with a high- or low-protein diet plus carnitine is less than without carnitine supplementation for rats ${ }^{12}$ and for catfish. ${ }^{13}$ However, piglets born to sows supplemented with L-carnitine grow faster than piglets born to control sows. ${ }^{14}$ L-carnitine supplementation increases the potential for oxygen transport and reduces plasma indicators of muscle damage in racing greyhounds. ${ }^{15}$ In addition, carnitine deficiency is associated with hyperammonemia ${ }^{16}$ and reduction in the production of angiotensin II. $^{17}$

On this basis, our objective was to investigate the effect of carnitine supplementation on the nutritional recovery of undernourished alcoholic rats. Our hypothesis was that 
carnitine given to malnourished rats would improve weight gain and recovery.

\section{MATERIALS AND METHODS}

All experimental procedures described followed the established guidelines for the care and use of laboratory animals according to law on animal welfare and were approved by the local office (Ribeirão Preto School of Medicine, São Paulo University, Brazil).

\section{Animals and diets}

Adult male Wistar rats weighing about $190 \mathrm{~g}$ from the Central Animal House of the University of São Paulo, Ribeirão Preto Campus, were housed in individual metal cages on a 12-h light:12-h dark cycle. Throughout the experiment, the animals received a Nuvilab ${ }^{\circledR}$ CR1 diet (Nuvital Nutrientes Ltda, Colombo, Paraná, Brazil) from a single lot. According to information provided by the manufacturer, the composition of the diet was as follows: moisture, $120 \mathrm{~g} / \mathrm{kg}$; protein, $220 \mathrm{~g} / \mathrm{kg}$; ether extract, 40 $\mathrm{g} / \mathrm{kg}$; mineral matter (maximum), $100 \mathrm{~g} / \mathrm{kg}$; fibrous matter (maximum), $89 \mathrm{~g} / \mathrm{kg}$; calcium (maximum), $14 \mathrm{~g} / \mathrm{kg}$; phosphorus (maximum), $8 \mathrm{~g} / \mathrm{kg} ; 6.75 \mathrm{mg}$ retinol activity equivalent; $52.5 \mu \mathrm{g}$ vitamin D3; $60 \mathrm{mg}$ vitamin $\mathrm{E} ; 12.5 \mathrm{mg}$ vitamin $\mathrm{K} 3 ; 14.4 \mathrm{mg} \mathrm{B}_{1} ; 11.0 \mathrm{mg} \mathrm{B}_{2} ; 12.0 \mathrm{mg} \mathrm{B}_{6} ; 60.0 \mu \mathrm{g} \mathrm{B} \mathrm{B}_{12}$; $60 \mathrm{mg}$ niacin; $112 \mathrm{mg}$ pantothenic acid; $6 \mathrm{mg}$ folic acid; $0.25 \mathrm{mg}$ biotin; $1.1 \mathrm{~g}$ choline; $50 \mathrm{mg} \mathrm{Fe;} 60 \mathrm{mg} \mathrm{Mn;} 60 \mathrm{mg} \mathrm{Zn;}$ $10 \mathrm{mg} \mathrm{Cu} ; 2 \mathrm{mg} \mathrm{I} ; 50 \mu \mathrm{g} \mathrm{Se} ; 1.5 \mathrm{mg} \mathrm{Co} ; 300 \mathrm{mg}$ DLmethionine; and $100 \mathrm{mg}$ L-lysine.

Six animals were first euthanized with a fresh $2.5 \%$ working stock tribromoethanol (Sigma-Aldrich, Steinheim, Germany; cat. T4, 840-2, lot 03509M1-071) solution, as the baseline group, and the remaining ones were divided into two groups $(n=30$ each) that received for 28 days half the diet consumed during the acclimation period. One group received water ad libitum and was denoted the malnourished control group without ethanol (malnutrition group), and the other received a $20 \%$ ethanol/water solution ad libitum, with no clear water, and was denoted the malnourished alcoholic test group (alcohol group). In parallel, a group of 12 animals received diet and water ad libitum as a general control (control group). After this period, 6 animals from each group were euthanized and the remaining ones were, again, subdivided. The malnourished animals were divided into the recovery group, which received a $100 \%$ control recovery diet ad libitum, and to a carnitine recovery group, which received a 100\% control recovery diet ad libitum plus carnitine. Similarly, the alcohol group was divided into the alcohol recovery group, which received the recovery diet alone, and to the carnitine alcohol recovery group, which received the recovery diet plus carnitine. Carnitine was administered daily by gavage at a concentration of $0.1 \mathrm{mg} / \mathrm{g}$ animal weight. ${ }^{5,11}$ Control animals received water alone by gavage. The animals were re-fed for 28 days. For the purposes of the present study, the day when the rats started their restricted diet was denoted day -28. The day when carnitine supplementation was started was day 0 . The end of the experimental period was day +28. Fig. 1 shows the experimental design. The experiment was carried out according to the Guide for the Care and Use of Laboratory Animals. ${ }^{18}$

\section{Analytical methods}

Urinary and hepatic nitrogen content was determined by the micro-Kjeldahl method. ${ }^{19}$ For this procedure, 24 -hour urine was collected into tubes containing $6 \mathrm{~N} \mathrm{HCl}$ and homogenized. The sample was first digested by placing $100 \mu \mathrm{l}$ of urine in a tube, in duplicate, to which $2 \mathrm{ml}$ of concentrated sulphuric acid $\left(\mathrm{H}_{2} \mathrm{SO}_{4}\right)$ and two drops of the selenium dioxide catalyst (5\%) were added. The sample was digested at $250{ }^{\circ} \mathrm{C}$ for 5 hours, distilled, and titrated with 0.1 $\mathrm{N}$ and $\mathrm{H}_{2} \mathrm{SO}_{4}$. Control analysis was performed by omitting urine samples from the procedures described above. The nitrogen content of the sample was calculated by the following formula: $\mathrm{N}=$ [SAS-BAS] * F/SW, where $\mathrm{N}=$ nitrogen, $\mathrm{g} / 100 \mathrm{~g}$; SAS = sample, amount of acid spent, ml; BAS = blank, amount of acid spent, $\mathrm{ml} ; \mathrm{F}=$ factor (ratio

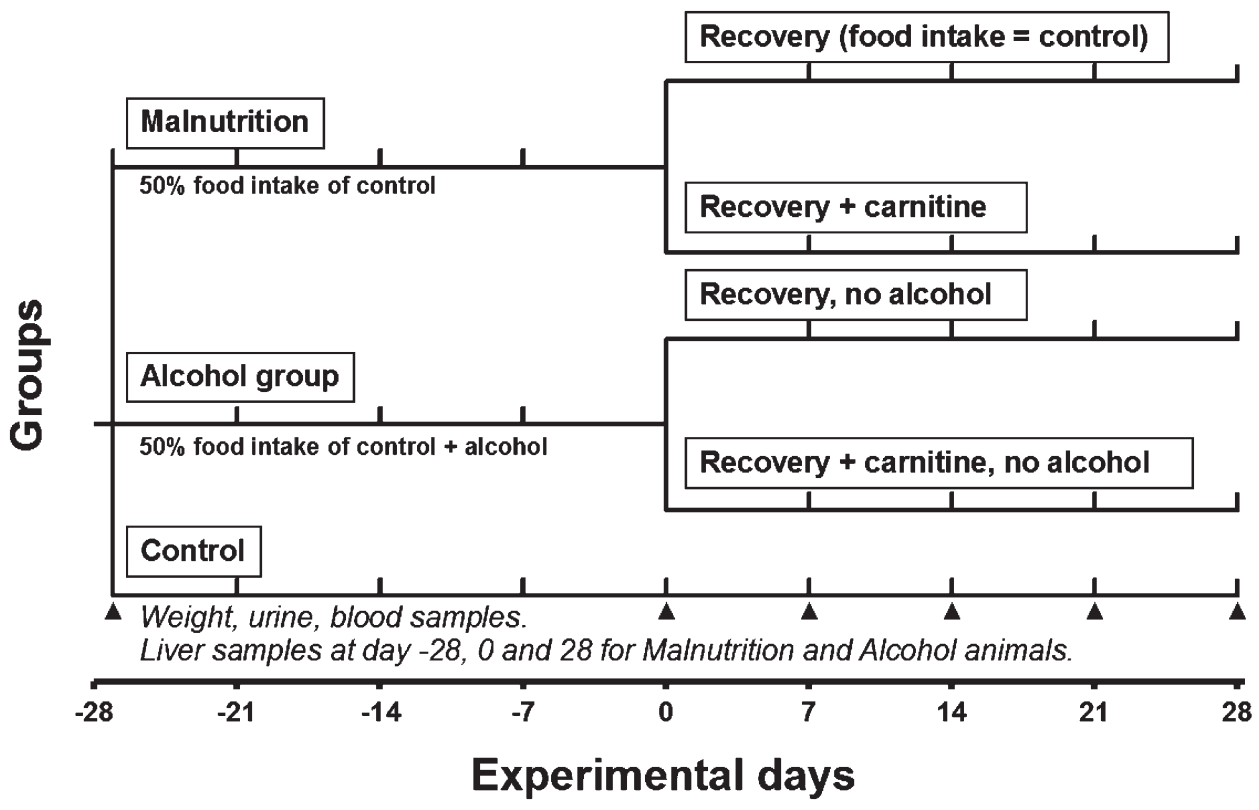

Figure 1 - Study design of the present experimental protocol. 
between the normality of the acid multiplied by the molecular weight of nitrogen by 100); SW = sample weight, g. For the determination of hepatic nitrogen, duplicate liver samples of 20 to $50 \mathrm{mg}$ were used according to the procedure described above.

Blood ethanol concentration $(\mathrm{mg} / \mathrm{g}$ ) was determined by head-space gas chromatography ${ }^{20}$ with a Shimadzu ${ }^{\circledR}$ instrument (model GC-17A, Shimadzu Corp, Kyoto, Japan) equipped with a flame ionization detector and a $30 \mathrm{~m} \times$ $0.25 \mathrm{~mm} \times 0.25$ micron DB-Wax ${ }^{\circledR}$ capillary column (J\&W Scientific, Courtaboeuf, France).

To determine total hepatic fat content, the livers of the animals were removed, weighed, and dried overnight in a ventilated oven at $100^{\circ} \mathrm{C}$. After drying, the livers were again weighed and ground. Total hepatic fat was determined by the Soxhlet method, ${ }^{19}$ with $50 \mathrm{mg}$ samples of dried liver being weighed in duplicate, placed on filter paper, folded, and introduced in the Soxhlet extractor, which was filled with petroleum ether and continuously heated at $60^{\circ} \mathrm{C}$ to permit solvent reflux until all of the fat present in the sample was dragged to a round flask, with the procedure lasting 6 hours. The flasks with the fat were then placed in an oven at $50^{\circ} \mathrm{C}$ until a constant weight was obtained. The amount of fat was then calculated as the difference between the weight of the flask before the beginning of the analysis and the weight at the end of the extraction process after the constant weight was established.

Plasma-free fatty acids were determined ${ }^{21}$ by gas chromatography using a model 5890 series II Hewlett Packard ${ }^{\circledR}$ apparatus (Palo Alto, CA, USA) equipped with a $30 \mathrm{~m} \times$ $0.32 \mathrm{~mm} \times 0.50$ micron 19091N-213 Innovax column (Agilent Technologies, Palo Alto, CA, USA) according to the method of Rose and Oklander. ${ }^{22}$ Plasma lysine and methionine content was determined by HPLC using a model LC 10AD Shimadzu ${ }^{\circledR}$ apparatus (Tokyo, Japan).

\section{Statistical analysis}

Data were analyzed statistically by the Wilcoxon test for two paired samples and by the Friedman test for more than two paired samples. When a significant difference was observed, the Dunn test was applied. The Mann-Whitney test was used for two unpaired samples and the KruskalWallis test was used for more than two samples. When a significant difference was observed, the Dunn test was applied. In all cases, the level of significance was set at $P<005$.

\section{RESULTS}

\section{Diet consumption}

During the undernourishment period, all groups received the same amount of diet; however, the diet consumption by these groups at the end of the recovery period showed significant differences between the carnitine recovery group and the carnitine alcohol recovery group animals, as well as between the carnitine alcohol recovery group and control group animals, with the carnitine alcohol recovery group animals consuming a smaller amount of diet. Differences in calorie consumption were also observed between these groups. Regarding the energy consumed during the undernourishment period, the alcohol group consumed, on average, $150 \mathrm{~kJ}$ more per day than the malnourished group animals (Table 1).

\section{Changes in body weight}

During the undernourishment period, from day -28 to day 0 , the mean body weight, as expected, of the malnourished animals without or with alcoholic malnourished animals was $51 \%$ and $28 \%$ lower $(P<005)$, respectively, than the controls. The weight of the malnourished group animals was $32 \%$ lower than that of alcoholic malnourished group animals $(P<0.05)$.

From day 0 to day +28 , the animals were re-fed, and the final weight of the recovery, carnitine recovery, alcohol recovery, and carnitine alcohol recovery groups was $22 \%$, $16 \%, 15 \%$, and $21 \%$ lower, respectively, than that of the control animals, with the groups differing from the control group $(P<0.05)$ but not from one another. Fig. 2 shows the weight range of the experimental groups during the experiment. This result does not demonstrate any action of carnitine on the weight gain of the animals under study.

Table 1 - Weight, diet consumption, and calorie consumption by the animals after the different experimental periods. ${ }^{1}$

\begin{tabular}{|c|c|c|c|c|}
\hline Period & Group* & Weight (g) & Diet consumption (g) & Energy consumption ( $\mathrm{kJ}$ ) \\
\hline Acclimatization (days -31 to -29 ) & All & $190 \pm 13^{a}$ & $22 \pm 4^{g}$ & $356 \pm 54^{n}$ \\
\hline \multirow[t]{3}{*}{ Undernourishment (days -28 to 0 ) } & Gmal & $176 \pm 90^{b}$ & $11 \pm 0^{\mathrm{h}}$ & $176 \pm 0^{\circ}$ \\
\hline & Galc & $257 \pm 29^{c}$ & $11 \pm 0^{\mathrm{h}}$ & $176 \pm 0^{\circ}+$ alcohol $^{2}$ \\
\hline & Gcon & $357 \pm 27^{d}$ & $29 \pm 2^{i}$ & $469 \pm 113^{p}$ \\
\hline \multirow[t]{5}{*}{ Recovery without or with carnitine (days +1 to +28 ) } & Grec & $351 \pm 90^{\mathrm{e}}$ & $31 \pm 6^{j}$ & $498 \pm 130^{q}$ \\
\hline & Gcar & $380 \pm 33^{\mathrm{e}}$ & $31 \pm 3^{j}$ & $498 \pm 130^{q}$ \\
\hline & Galcrec & $385 \pm 25^{\mathrm{e}}$ & $28 \pm 2^{\mathrm{j}}$ & $452 \pm 117^{q}$ \\
\hline & Galccar & $355 \pm 39^{e}$ & $26 \pm 2^{1}$ & $419 \pm 109^{r}$ \\
\hline & Gcon & $451 \pm 21^{f}$ & $32 \pm 3^{m}$ & $515 \pm 134^{s}$ \\
\hline
\end{tabular}

\footnotetext{
${ }^{1}$ Values are means \pm SD. Different letters: $P<0.05$

${ }^{2}$ Equivalent to $150 \mathrm{~kJ} / \mathrm{day}$

*Groups

Gmal: malnourished animals

Galc: alcohol malnourished animals

Gcon: control animals ingesting an ad libitum diet throughout the experiment

Grec: recovery malnourished animals re-fed with an ad libitum diet, without alcohol and without carnitine

Gcar: malnourished animals re-fed with a carnitine-supplemented diet, without alcohol

Galcrec: alcoholic malnourished animals re-fed with an ad libitum diet, without alcohol and without carnitine

Galccar: alcoholic malnourished animals re-fed with a carnitine-supplemented diet, without alcohol
} 


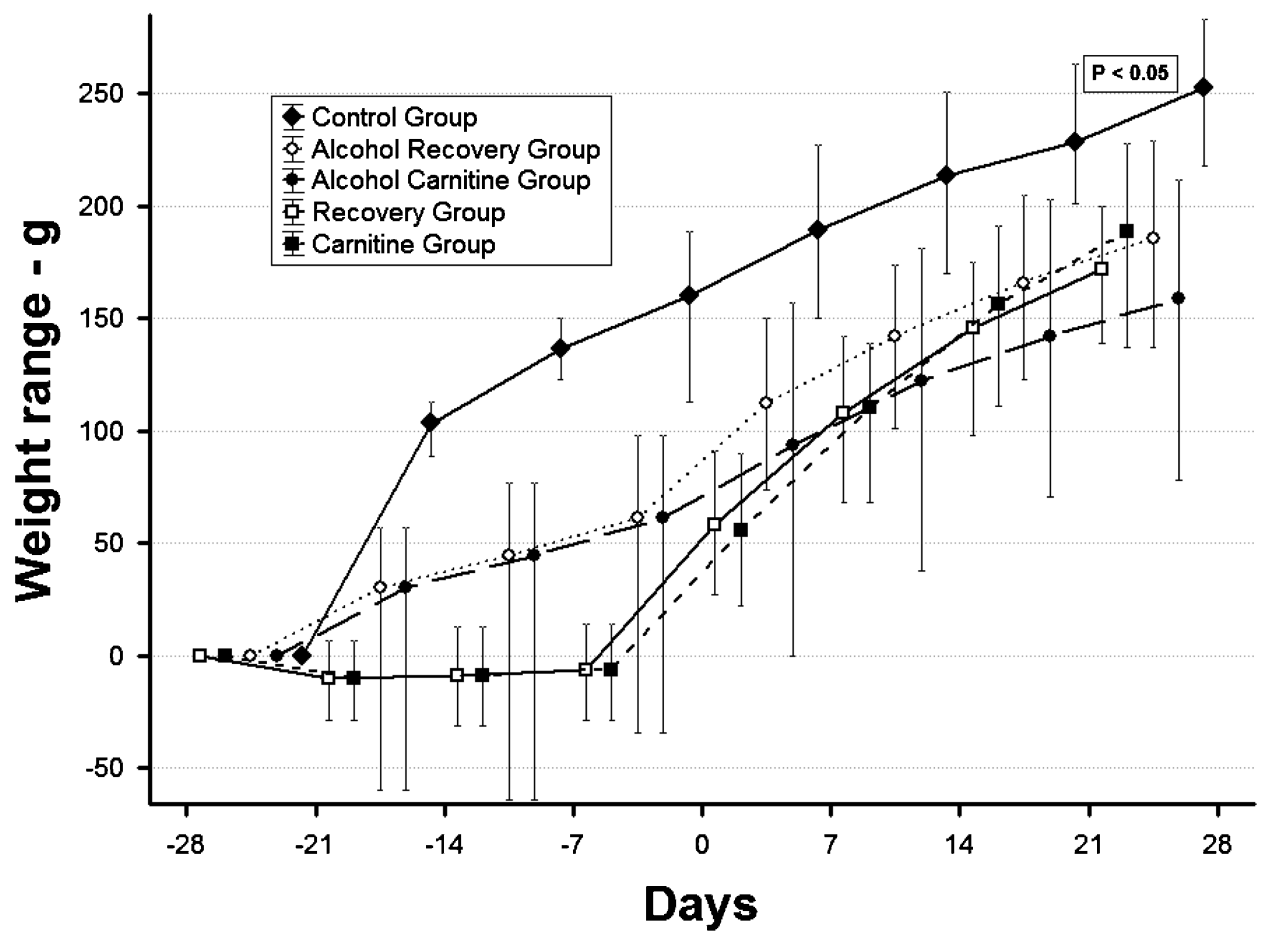

Figure 2 - Mean, minimum, and maximum variation in weight during the experimental protocol in relation to baseline. Control animals ingesting an ad libitum diet throughout the experiment. Alcohol recovery malnourished animals re-fed with an ad libitum diet, no alcohol. Alcohol Carnitine recovery malnourished animals re-fed with a carnitine-supplemented, ad libitum, no alcohol. Recovery malnourished animals re-fed with ad libitum diet. Carnitine malnourished animals re-fed with a carnitinesupplemented diet, ad libitum.

\section{Blood alcohol content}

On average, the alcoholic malnourished group animals consumed approximately $25 \mathrm{ml}$ of a $20 \%$ ethanol solution per day from day -28 to day 0 . The mean blood alcohol levels obtained are presented in Table 2. We observed that on day -14 , blood alcohol levels were significantly higher than on day 0 . The alcoholic malnourished group animals received ethanol only during the undernourished period. Other animals did not receive ethanol.

\section{Urinary nitrogen}

Table 2 shows urinary nitrogen excretion. It was reduced at the end of the undernourishment period, with a difference between the recovery group and carnitine alcoholic malnourished group animals $(\mathrm{P}<0.05)$. During the first week of the recovery period, there was increased urinary nitrogen excretion, with this increase being more marked in the alcoholic malnourished with or without carnitine groups, whereas at the end of the recovery period, there was no significant difference between groups. This result shows that carnitine supplementation had no effect on urinary nitrogen excretion. A significant nitrogen urine difference was observed after the recovery $(\sim 0,39 \mathrm{~g} / \mathrm{d})$ and the undernourishment $(\sim 0.15 \mathrm{~g} / \mathrm{d})$ periods.

\section{Nitrogen and fat liver content}

At the beginning of the experiment, mean hepatic nitrogen was $1.67 \mathrm{~g} / 100 \mathrm{~g}$ liver. At the end of the undernourishment period, the malnourished group animals had a mean hepatic nitrogen amount of $2.9 \mathrm{~g} / 100 \mathrm{~g}$, a value significantly different from the basal one. The amount of hepatic nitrogen in the malnourished animals was significantly higher than that observed in the alcoholic malnourished animals.

The amount of hepatic nitrogen increased in the carnitine recovery group animals (3.3 g/100 g) but decreased in the recovery group animals $(2.4 \mathrm{~g} / 100 \mathrm{~g})$. However, at the end of the recovery period, there were no significant differences in the values for these two groups compared to the end of the undernourishment period.

After the 28 days of recovery, the alcohol recovery group animals without or with carnitine presented a mean amount of nitrogen of 1.52 and $1.44 \mathrm{~g} / 100 \mathrm{~g}$ liver, respectively, values similar to those obtained during the basal period and at the end of the undernourishment period (Table 2). Again, this result did not demonstrate an action of carnitine in the animals studied.

Total hepatic fat content differed between the malnourished group animals. At the end of the undernourishment period, total hepatic fat content was significantly decreased in animals that did not receive alcohol compared to the beginning of the experiment. Liver fat content was significantly increased in alcoholic malnourished animals.

On the 28th day of recovery, alcoholic malnourished animals, without or with carnitine, had a hepatic fat content similar to that observed at the end of the undernourishment period, with no significant differences between these periods. Thus, it should be emphasized also that carnitine did not affect the reduction of hepatic fat. The hepatic fat content of the non-alcoholic malnourished groups, without or with carnitine, increased during this period, with a recovery of basal values (Table 2). 
Table 2 - Data from different groups during the experimental protocol.

\begin{tabular}{|c|c|c|c|c|c|c|c|c|c|}
\hline & & $\begin{array}{l}\text { Plasma } \\
\text { alcohol }\end{array}$ & Urine nitrogen & Hepatic nitrogen & Hepatic fat & $\begin{array}{l}\text { Plasma free } \\
\text { fatty acid }\end{array}$ & $\begin{array}{l}\text { Plasma } \\
\text { lysine }\end{array}$ & $\begin{array}{c}\text { Plasma } \\
\text { methionine }\end{array}$ & $\begin{array}{l}\text { Plasma } \\
\text { glycine }\end{array}$ \\
\hline Group* & Day & $g / l$ & $g / d$ & $g / 100 g$ & $g / 100 g$ & $\mathrm{mEq} / \mathrm{l}$ & $\mu \mathrm{mol} / \mathrm{l}$ & $\mu \mathrm{mol} / \mathrm{I}$ & $\mu \mathrm{mol} / \mathrm{l}$ \\
\hline Baseline & -28 & 0 & $0.23 \pm 0.06$ & $1.7 \pm 0.2 \dagger$ & $7.6 \pm 1.1$ & $0.72 \pm 0.13$ & $36 \pm 13 \dagger$ & $58 \pm 17$ & $9 \pm 4$ \\
\hline Gmal & 0 & 0 & $0.16 \pm 0.03 \dagger$ & $2.9 \pm 0.7$ & $4.9 \pm 2.0 \dagger$ & $0.84 \pm 0.38$ & $13 \pm 5 \dagger$ & $20 \pm 9 \dagger$ & $5 \pm 2$ \\
\hline Grec & +28 & 0 & $0.33 \pm 0.04$ & $2.4 \pm 0.4$ & $9.2 \pm 2.1$ & $0.44 \pm 0.11 \dagger$ & $61 \pm 6$ & $56 \pm 3$ & $5 \pm 3$ \\
\hline Gcar & +28 & 0 & $0.38 \pm 0.06$ & $3.3 \pm 0.2 \dagger$ & $7.6 \pm 0.7$ & $0.42 \pm 0.12 \dagger$ & $53 \pm 16$ & $42 \pm 11$ & $4 \pm 3$ \\
\hline Galc & -14 & $0.7 \pm 0.1 \dagger$ & & & & & & & \\
\hline Galc & 0 & $0.2 \pm 0.1$ & $0.15 \pm 0.02 \dagger$ & $1.5 \pm 0.1$ & $10.3 \pm 2.1$ & $1.45 \pm 0.07$ & $15 \pm 7 \dagger$ & $38 \pm 9$ & $2 \pm 1 \dagger$ \\
\hline Galcrec & +28 & 0 & $0.40 \pm 0.12$ & $1.5 \pm 0.2$ & $10.4 \pm 3.9$ & $0.88 \pm 0.07$ & $39 \pm 11$ & $52 \pm 8$ & $4 \pm 1$ \\
\hline Galccar & +28 & 0 & $0.44 \pm 0.18$ & $1.5 \pm 0.1$ & $9.8 \pm 1.4$ & $1.20 \pm 0.23$ & $39 \pm 6$ & $50 \pm 2$ & $2 \pm 1 \dagger$ \\
\hline
\end{tabular}

*See figure 1 for experimental design detail.

*Groups

Gmal: malnourished animals

Grec: recovery malnourished animals re-fed with an ad libitum diet, without alcohol and without carnitine

Gcar: malnourished animals re-fed with a carnitine-supplemented diet, without alcohol

Galc: alcoholic malnourished animals

Galcrec: alcoholic malnourished animals re-fed with an ad libitum diet, without alcohol and without carnitine

Galccar: alcoholic malnourished animals re-fed with a carnitine-supplemented diet, without alcohol

${ }^{\dagger} \mathrm{P}<0.05$. Values are means \pm SD.

Fig. 3 shows the presence of a negative correlation between hepatic fat and nitrogen content throughout the experiment.

\section{Plasma free fatty acids}

Plasma free fatty acids did not differ from those observed during the basal period in the malnourished animals $(\sim 0.57 \mathrm{mEq} / \mathrm{l})$ but were significantly different from the alcoholic malnourished $(\sim 1.18 \mathrm{mEq} / \mathrm{l})$ group. Analysis of the recovery period showed that plasma free fatty acid content was reduced in all groups regardless of whether Lcarnitine had been used as a supplement. The animals of the

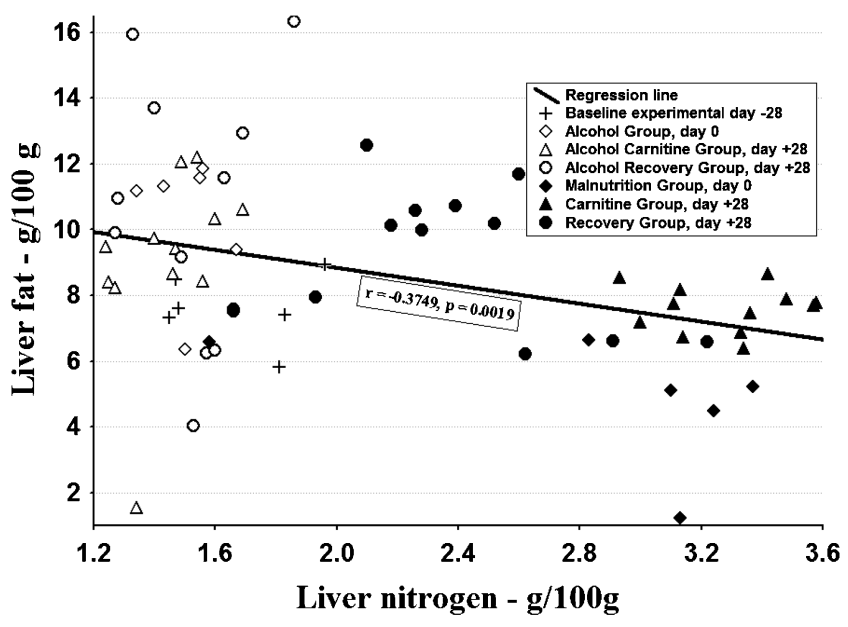

Figure 3 - Relation between liver nitrogen and liver fat during the experimental protocol. Note that undernourished alcoholic rats had lower hepatic nitrogen values and higher hepatic fat values.

Control animals ingesting an ad libitum diet throughout the experiment. Alcoholic malnourished + alcohol animals. Alcohol carnitine recovery malnourished animals re-fed with a carnitinesupplemented, ad libitum, no alcohol. Alcohol recovery malnourished animals re-fed with an ad libitum diet, no alcohol. Carnitine malnourished animals re-fed with a carnitine-supplemented diet, ad libitum. Recovery malnourished animals re-fed with ad libitum diet. alcoholic group supplemented with carnitine had higher free fatty acid levels $(1.20 \mathrm{mEq} / \mathrm{l})$ than the recovery malnourished animals, without or with carnitine $(\sim 0.43 \mathrm{mEq} / \mathrm{l})$ (Table 2).

\section{Plasma lysine and methionine}

Plasma lysine and methionine concentrations were decreased at the end of the undernourishment period, increasing again when the animals were submitted to nutritional recovery. At the end of the recovery period, the alcoholic malnourished groups presented a lower plasma lysine concentration than the malnourished groups. No action of carnitine was observed in these animals (Table 2).

\section{DISCUSSION}

The results of the present investigation show that it was possible to induce undernourishment in animals receiving half the amount of the diet given to the controls. Thus, after 28 days of undernourishment, the weight of the animals ranged from $50 \%$ to $75 \%$ of the control weight. Similarly to what occurs in undernourished hospitalized patients, therefore, the present protocol was considered to be adequate to induce undernourishment and to permit the study of the effect of re-feeding with an alcohol-free diet, supplemented with carnitine or not. ${ }^{23}$

The blood alcohol content of these animals varied in a significant manner, in agreement with previous literature reports. $^{24,25}$ The weight of the undernourished animals receiving alcohol was less compromised. The lower weight loss of rats receiving alcohol cannot be explained by a greater food intake since both undernourished groups received the same amount of food. Another possibility is the offer of alcohol as a caloric food, as previously described, ${ }^{26,27}$ as well as the possibility of water retention. However, no edema was clinically detected in the animals. The relationship between alcohol consumption and body weight is controversial among some investigators, ${ }^{28,29}$ suggesting that the utilization of ethanol-derived calories is inefficient. However, in situations of protein-calorie restriction such as the one to which these animals were submitted, the calories provided by 
alcohol may be utilized with the same efficiency as the other nutrients despite the high alcohol consumption. Da-Silva et al. ${ }^{30}$ and Aguiar et al. ${ }^{31}$, in studies of animals receiving a $20 \%$ ethanol solution and $50 \%$ of the control diet, obtained similar data, indicating that ethanol consumption attenuates the weight loss of malnourished animals. Weight gain was evident with the re-feeding process, and both animal groups had similar weight at the end of the protocol, though it was $25 \%$ lower than control, in agreement with the data obtained by Feng et al. ${ }^{32}$

At the end of the period of undernourishment, the hepatic fat content of undernourished alcoholic rats was significantly higher, i.e., about $50 \%$ more than the weight of undernourished animals that did not receive alcohol. In parallel, the levels of plasma free fatty acids were also higher among the alcoholic undernourished animals. Along with a lower fat content, hepatic nitrogen content was higher in the undernourished rats receiving no alcohol. Both groups recovered their weight with the ad libitum offer of diet and the removal of alcohol. However, carnitine had no detectable effect when offered to previously undernourished rats. Thus, rats who had received ethanol during the period of undernourishment continued to have higher hepatic fat content, lower nitrogen levels, and higher plasma free fatty acid levels. These higher free fatty acid levels and greater liver fat content of rats receiving ethanol may suggest that ethanol functioned as a source of calories in these animals, favoring the synthesis of fat, even though the literature has reported an effective action of carnitine on the reduction of plasma lipids in rats chronically treated with ethanol. $^{33,34}$ Thus, at the end of the undernourishment period, the weight of these rats would be lower than control (as was indeed the case) but would be higher than that of undernourished rats receiving no alcohol (as was also the case). It has been reported that carnitine protects against rat liver injury ${ }^{10,35}$ and an increase in reactive oxygen species ${ }^{36}$ observed in mice on an oxidant challenge diet. However, in this study, the offer of carnitine was not enough to modify or implement weight recovery, plasma free fatty acid levels, or liver fat content.

Regarding the plasma levels of lysine and methionine, which were reduced after the period of undernourishment (independently of the presence of alcohol), there was recovery with the offer of nutrients, with carnitine, once again, having no effect. The only indicator observed in rats receiving carnitine was a higher content of hepatic nitrogen. The data also showed a negative correlation between hepatic fat content and nitrogen. Thus, the greater the hepatic fat content was, the lower the quantity of hepatic nitrogen was. In addition, high liver carnitine content is also found in rats on ethanol for four weeks, and that may explain why carnitine supplementation had no effect on fat liver content. ${ }^{37}$

Large numbers of studies have been conducted in the search for an adjuvant for the treatment of hospital malnutrition. The present experimental design was constructed in order to simulate a situation similar to that observed in malnourished and in alcoholic malnourished patients and to determine the possible efficacy of carnitine as a supplement capable of contributing to the recovery of nutritional status in these patients. Therefore, the paper is descriptive and did not study the biochemical effects of carnitine, i.e., the expression or activity of carnitine palmitoyltransferase $\mathrm{I}^{38}$ or gene expression involved in hepatic $\beta$-oxidation or secretion of lipoproteins. However, under the present experimental conditions, carnitine supplementation did not prove to be an adjuvant for the recovery of nutritional status by the animals, suggesting that the indication of carnitine as supplementation should be carefully re-evaluated.

\section{ACKNOWLEDGMENTS}

The present study was supported by grants from the Brazilian Fundação de Amparo à Pesquisa do Estado de São Paulo - FAPESP (no. 01/12736-4) and Brazilian Conselho Nacional de Pesquisa - CNPq (no. 306824).

\section{REFERENCES}

1. Santos JE, Vannucchi H, Marchini JS, Oliveira JED. Nutritional care of hospitalized patients in Brazil with particular reference to pellagra and alcoholism as complicating factors. Prog Clin Biol Res. 1981;77:719-27.

2. Hoffer LJ. Clinical nutrition: 1. Protein-energy malnutrition in the inpatient. Can Med Assoc J. 2001;165:1345-9.

3. Stickel F, Hoehn B, Schuppan D, Seitz HK. Review article: nutritional therapy in alcoholic liver disease. Aliment Pharmacol Ther. 2003;18:35773, doi: 10.1046/j.1365-2036.2003.01660.x.

4. Tanphaichitr V, Lerdvuthisopon N, Dhanamitta S, Broquist HP. carnitine status in Thai adults. Am J Clin Nutr. 1980;33:876-80.

5. Alp H, Orbak Z, Akçay F, Tan H, Aksoy H. Plasma and urine carnitine levels and carnitine supplementation in children with malnutrition. J Trop Pediatr. 1999;45:294-6, doi: 10.1093/tropej/45.5.294.

6. Brass EP. Supplemental carnitine and exercise. Am J Clin Nutr. 2000;72:618S-23S.

7. Hoppel CL. Carnitine and carnitine palmitoyltransferase in fatty acid oxidation and ketosis. Fed Proc. 1982;41:2853-7.

8. Broquist HP, Borum PR. Carnitine biosynthesis: nutritional implications. Adv Nutr Res. 1982;4:181-204.

9. Rudman D, Sewell CW, Ansley JD. Deficiency of carnitine in cachectic cirrhotic patients. J Clin Invest. 1977;60:716-23, doi: 10.1172/JCI108824.

10. Bykov I, Järveläinen $\mathrm{H}$, Lindros K. L-carnitine alleviates alcohol-induced liver damage in rats: role of tumour necrosis factor-alpha. Alcohol Alcohol. 2003;38:400-6.

11. Portari GV, Camelo JS, Rabito EI, Marchini JS, Jordão AA. Effect of treatment with DL-carnitine after acute alcoholization in rats. Scand J Lab Anim Sci. 2008;35:191-6.

12. Ahern DA, Mitchell ME. Liver function in protein energy malnutrition measured by cinnamic acid tolerance and benzoic acid tolerance: effect of carnitine supplementation. Br J Nutr. 1989;61:209-21, doi: 10.1079/ BJN19890110.

13. Ozorio RO, Uktoseja JL, Huisman EA, Verreth JA. Changes in fatty acid concentrations in tissues of African catfish, Clarias gariepinus Burchell, as a consequence of dietary carnitine, fat and lysine supplementation. Br J Nutr. 2001;86:623-36, doi: 10.1079/BJN2001447.

14. Birkenfeld C, Kluge H, Eder K. L-carnitine supplementation of sows during pregnancy improves the suckling behaviour of their offspring. Br J Nutr. 2006;96:334-42, doi: 10.1079/BJN20061833.

15. Epp TS, Erickson HH, Woodworth J, Poole DC. Effects of oral L-carnitine supplementation in racing Greyhounds. Equine Comp Exerc Physiol. 2007;4:141-7.

16. Limketkai BN, Zucker SD. Hyperammonemic encephalopathy caused by carnitine deficiency. J Gen Intern Med. 2008;23:210-3, doi: 10.1007/ s11606-007-0473-0.

17. Davis PA, Mormino P, Savica P, Calò LA. L-carnitine, inflammation and hypertension. Nephrology. 2009;14:264-5.

18. National Research Council. Guide for the care and use of laboratory animals, second printing Washington, DC: National Research Council, National Academy of Sciences, 1996

19. AOAC. Official Methods of Analysis, 13th ed. Washington, DC: Association of Official Analytical Chemists, 1980.

20. Jones AW, Andersson L. Comparison of ethanol concentrations in venous blood and end-expired breath during a controlled drinking study. Forensic Sci Int. 2003;132:18-25, doi: 10.1016/S0379-0738(02)00417-6.

21. Ducombe WG. The colorimetric micro-determination of non-esterified fatty acids in plasma. Clin Chim Acta. 1964;9:122-5, doi: 10.1016/00098981(64)90004-X.

22. Rose HG, Oklander RM. Improved procedure for extraction of lipids from human erythrocytes. J Lipid Res. 1965;6:428-9.

23. Waitzberg DL, Caiaffa WT, Correia MITD. Hospital malnutrition: the Brazilian National Survey (IBRANUTRI): A study of 4000 patients. Nutrition. 2001;17:578-80, doi: 10.1016/S0899-9007(01)00573-1.

24. De Carli LM, Lieber CS. Fatty liver in the rat after prolonged intake of ethanol with a nutritionally adequate new liquid diet. J Nutr. 1967;91:331-6. 
25. Gil-Martin E, Calvo P, Fernandez-Briera A. Chronic alcoholization in rats by free-choice ingestion of a hydroalcoholic solution. Food Chem Toxicol. 1998;36:941-6, doi: 10.1016/S0278-6915(98)00042-8.

26. Suter PM, Schutz Y, Jequier E. The effect of ethanol on fat storage in healthy subjects. N Engl J Med. 1992;326:983-7, doi: 10.1056/ NEJM199204093261503.

27. Sonko BJ, Prentice AM, Murgatroyd PR, Goldberg GR, van de Ven ML, Coward WA. Effect of alcohol on postmeal fat storage. Am J Clin Nutr. 1994;59:619-25.

28. Lieber CS. The influence of alcohol on nutritional status. Nutr Rev. 1988;46:241-54, doi: 10.1111/j.1753-4887.1988.tb05443.x.

29. Colditz GA, Giovannucci E, Rimm EB, Stampfer MJ, Rosner B, Speizer FE, Gordis E, Willett WC. Alcohol intake in relation to diet and obesity in women and men. Am J Clin Nutr. 1991;54:49-55.

30. Silva VA, Kopelman BI, Macellaro MT, Smizd JS, Freitas CA. Interação entre a desnutrição e o consumo de etanol antes e durante a gestação: efeitos sobre o desenvolvimento e comportamento da prole de ratos. / Interactions between malnutrition and ethanol consumption before and during pregnancy - effects on the development and behavior of the offspring of rats. J Pediatr. (Rio J). 1982;53:306-13.

31. Aguiar AS, Da-Silva VA, Boaventura GT. Can calories from ethanol contribute to body weight preservation by malnourished rats? Braz J Med Biol Res. 2004;37:841-6, doi: 10.1590/S0100-879X2004000600009.
32. Feng Y, Guo C, Wei J, Yang J, Ge Y, Gao L. Necessity of carnitine supplementation in semistarved rats fed a high-fat diet. Nutrition. 2001;17:628-31, doi: 10.1016/S0899-9007(01)00601-3.

33. Sachan DS, Rhew TH, Ruark RA. Ameliorating effects of carnitine and its precursors on alcohol-induced fatty liver. Am J Clin Nutr. 1984;39: 738-44.

34. Bahcecioglu IH, Demir A, Ustundag B, et al. Protective effect of L-carnitine on alcoholic fatty liver in rats. Med Sci Res. 1999;27: 475-8.

35. Fischer M, Hirche F, Kluge H, Eder K. A moderate excess of dietary lysine lowers plasma and tissue carnitine concentrations in pigs. Br J Nutr. 2009;101:190-6, doi: 10.1017/S0007114508994770.

36. Suchy I, Chan A, Shea TB. Dietary supplementation with a combination of $\alpha$-lipoic acid, acetyl-L-carnitine, glycerophosphocoline, docosahexaenoic acid, and phosphatidylserine reduces oxidative damage to murine brain and improves cognitive performance. Nutr Res. 2009;29:70-4, doi: 10.1016/j.nutres.2008.11.004

37. Kondrup J, Grunnet N. The effect of acute and prolonged ethanol treatment on the contents of co-enzyme A, carnitine and their derivatives in rat liver. Biochem J. 1973;132: 373-9.

38. Petta S, Muratore C, Craxi A. Non-alcoholic liver disease pathogenesis: the present and the future. Dig Liver Dis. 2009;41:615-25, doi: 10.1016/j. dld.2009.01.004. 